\title{
ПОВЫШЕНИЕ ИНВЕСТИЦИОННОЙ ПРИВАЕКАТЕАЬНОСТИ РЕГИОНА КАК ФАКТОР ИННОВАЦИОННОГО РАЗВИТИЯ
}

\begin{abstract}
Аннотауия. Џель работы. Џелью настоящей статьи является исследование механизмов активизации инновационной деятельности в регионе за счет роста инвестииионной привлека-

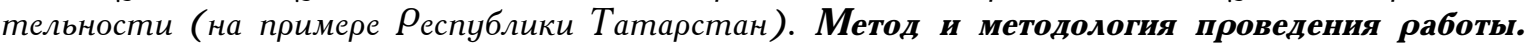
Настоящая статья основана на общенаучных методах, предусматривающих применение системного подхода к решению научных проблем. В основе данной работы лежат фундаментальные труды отечественных ученых-экономистов, посвященные проблемам управления инновациям. Результаты. Инвестиционная привлекательность региона и уровень его инновационного развития является взаимозависимыми факторами, и при росте одного неизменно повышается и другой. В статье рассмотрены федеральные целевые программы с цеелью определения эффективности их реализации, а также проанализированы прямые иностранные инвестищии в эко-

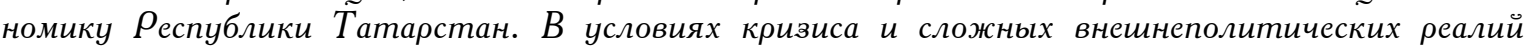
основным источником инвестииий в рисковые венчурные проекты остается государство. Автором проанализированы федеральные целевые программы, просчитана их эффективность. Об-

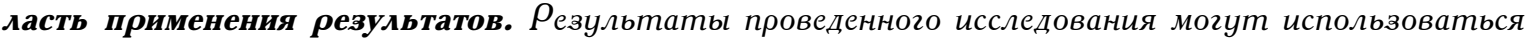
исполнительными органами государственной власти при формировании региональной инновационной политики. Выводы. Государственные инвестиционные программы реализуются с эффективностью ниже единицы, что оббясняется направленностью федеральных иелевых программ скорее на получение социального эффекта, нежели экономического. Иностранные инвестииии в

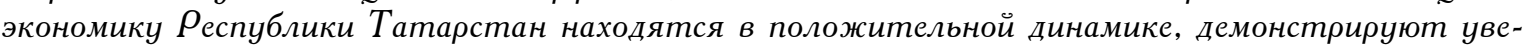
ренный $о$ ост.
\end{abstract}

Ключевые слова: инвестиционная привлекательность региона, инновационное развитие, инновационная деятельность, федеральная целевая программа, региональная инновационная система.

\section{ZAYNULLINA DILYARA RAMILEVNA \\ $\rho_{h} D$ Econ., senior teacher of Examination and Real Estate Administration department FGBOOU WAUGH "Kazan state architectural and construction university", e-mail: zaynullina@kgasu.ru}

\section{IMPROVING THE INVESTMENT ATTRACTIVENESS OF THE REGION AS A FACTOR OF INNOVATIVE DEVELOPMENT}

\begin{abstract}
The goal of the present manuscript is researching the mechanisms of activation of innovative activity in the region due to a growth of investment attractiveness (using the case study of the Republic of Tatarstan). The present manuscript is based on general scientific methods stipulating the use of a systemic approach to solving scientific problems. The basis for this study are major works of domestic scientists-economists devoted to problems of management of innovations. The manuscript discusses federal targeted programs in order to determine the effectiveness of their implementation, as well as analyzing direct foreign investments into the economy of the Republic of Tatarstan. The author has analyzed federal targeted programs, and has calculated their effectiveness. The results of the study completed may be used by the executive governmental authorities when forming the regional investment policy. State investment programs are implemented with the effectiveness below one which is explained by the focus of federal targeted programs that is more likely to be directed towards obtaining a social effect than an economic one. Foreign investments into the economy of the Republic of Tatarstan are in a positive dynamics and demonstrate a consistent growth.
\end{abstract}

Keywords: the investment attractiveness of the region, innovative development, an innovative activity, a federal targeted program, a regional innovative system. 
Введение. Уровень инновационного развития региона напрямую зависит от инвестиционной привлекательности региона, и, наоборот, с целью привлечения инвестиций в инновации надо формировать привлекательный для инвесторов инвестиционный климат в регионе. Для повышения региональной инвестиционной привлекательности в том числе и принят Федеральный закон от 23.08.1996 № 127-Ф3 «О науке и государственной научнотехнической политике», предполагающий государственною поддержку субъектов инновационной деятельности, отвечающих требованиям законодательства. Необходимо подчеркнуть, что без инвестиций невозможны инновации, только дополнительные финансовые вложения могут привести к получению научно-технических результатов и их дальнейшей коммерциализации. И в случае если частный бизнес не готов инвестировать в инновационные проекты, то государство должно взять этот вопрос на себя, хотя бы на время запуска всего механизма.

Основной раздел

Одним из крупнейших источников инвестирования в Российской Федерации является государство, которое действует посредством реализации федеральных целых программ. В таблице 1 проанализированы наиболее крупные ФЦП, реализуемые в России, сделана попытка определить их эффективность.

Таблица 1

Федеральные целевые программы и их эффективность

\begin{tabular}{|c|c|c|c|c|c|}
\hline $\begin{array}{c}\text { Название } \\
\text { программы }\end{array}$ & $\begin{array}{c}\text { Период } \\
\text { реализации }\end{array}$ & $\begin{array}{c}\text { Назначение } \\
\text { (цели, задачи) }\end{array}$ & \begin{tabular}{|c|} 
Фактические \\
затраты \\
(сколько де- \\
нег выделили)
\end{tabular} & $\begin{array}{l}\text { Фактические } \\
\text { результаты } \\
\text { (сколько по- } \\
\text { тратили) }\end{array}$ & $\begin{array}{l}\text { Коэффициент } \\
\text { экономиче- } \\
\text { ской эффек- } \\
\text { тивности }\end{array}$ \\
\hline \multirow{2}{*}{ «Жилище» } & \multirow{2}{*}{$\begin{array}{c}2016-2020 \\
\quad \text { годы }\end{array}$} & \multirow{2}{*}{$\begin{array}{l}\text { Улучшение жилищных усло- } \\
\text { вий граждан за счет развития } \\
\text { рынка экономичного и эколо- } \\
\text { гичного жилья. }\end{array}$} & $\begin{array}{l}69945,86 \text { млн } \\
\text { руб. (на } 2017 \\
\text { год) }\end{array}$ & \multirow{2}{*}{$\begin{array}{c}54343,56 \text { млн } \\
\text { руб. }\end{array}$} & \multirow{2}{*}{0,77} \\
\hline & & & \begin{tabular}{|c|}
124168,94 млн \\
руб. (прогноз \\
на 2020 год)
\end{tabular} & & \\
\hline \multirow{2}{*}{$\begin{array}{c}\text { «Устойчивое } \\
\text { развитие сель- } \\
\text { ских террито- } \\
\text { рий» }\end{array}$} & \multirow{2}{*}{$\begin{array}{c}2014-2017 \\
\text { годы }\end{array}$} & \multirow{2}{*}{$\begin{array}{l}\text { Повышение качества и уровня } \\
\text { жизни сельского населения, } \\
\text { развитие сельской социальной } \\
\text { инфраструктуры, техническое } \\
\text { обустройство сельской местно- } \\
\text { сти. }\end{array}$} & $\begin{array}{l}10020,00 \text { млн } \\
\text { руб. (на } 2017 \\
\text { год) } \\
\end{array}$ & \multirow{2}{*}{$\begin{array}{c}10011,00 \text { млн } \\
\text { руб. }\end{array}$} & \multirow{2}{*}{0,99} \\
\hline & & & $\begin{array}{c}9012,30 \text { млн } \\
\text { руб. (прогноз } \\
\text { на } 2018 \text { год) }\end{array}$ & & \\
\hline \multirow{2}{*}{$\begin{array}{c}\text { «Развитие } \\
\text { физической } \\
\text { культуры и } \\
\text { спорта в Рос- } \\
\text { сийской Феде- } \\
\text { рации» }\end{array}$} & \multirow{2}{*}{$\begin{array}{c}\text { 2016-2020 } \\
\text { годы }\end{array}$} & \multirow{2}{*}{$\begin{array}{l}\text { Развитие спортивной инфра- } \\
\text { структуры, популяризация } \\
\text { профессионального спорта, } \\
\text { приобщение граждан к регу- } \\
\text { лярным занятиям физической } \\
\text { культурой. }\end{array}$} & $\begin{array}{l}14259,91 \text { млн } \\
\text { руб. (на } 2017 \\
\text { год) }\end{array}$ & \multirow{2}{*}{$\begin{array}{c}14249,91 \text { млн } \\
\text { руб. }\end{array}$} & \multirow{2}{*}{0,99} \\
\hline & & & \begin{tabular}{|c|}
$128015,52 \mathrm{млн}$ \\
руб. (прогноз \\
на 2018 год)
\end{tabular} & & \\
\hline \multirow{2}{*}{$\begin{array}{c}\text { «Развитие } \\
\text { транспортной } \\
\text { системы Рос- } \\
\text { сии» }\end{array}$} & \multirow{2}{*}{$\begin{array}{c}2010-2021 \\
\text { годы }\end{array}$} & \multirow{2}{*}{$\begin{array}{l}\text { Развитие транспортной инфра- } \\
\text { структуры, повышение доступ- } \\
\text { ности транспортных услуг для } \\
\text { граждан, реализация транзит- } \\
\text { ного потенциала страны. }\end{array}$} & \begin{tabular}{|c|}
377544,42 млн \\
руб. (на 2017 \\
год) \\
\end{tabular} & \multirow{2}{*}{$\begin{array}{c}385700,00 \text { млн } \\
\text { руб. }\end{array}$} & \multirow[b]{2}{*}{1,02} \\
\hline & & & $\begin{array}{c}1101336,100 \\
\text { млн руб. } \\
\text { (прогноз на } \\
2018 \text { год) }\end{array}$ & & \\
\hline
\end{tabular}

Примечание: составлено автором.

Из таблицы видно, что большинство государственных инвестиционных программ реализуется с эффективностью ниже единицы, что объясняется направленностью федеральных целевых программ скорее на получение социального эффекта, нежели экономического. Однако частные лица инвестируют лишь в объекты, имеющие высокую инвестиционную при- 
влекательность и оправдывающие вложение денежных средств.

К сожалению, ввиду повышенного уровня неопределенности инвестирование инновационных проектов - еще менее привлекательное вложение для инвесторов. Сложность проблемы недостаточной реализации инноваций, влияющих на качественную составляющую роста экономики, состоит в отсутствии спроса на научно-технические продукты, а также в преобладании доли сырьевых отраслей в экономике, в нежелании предприятий менять старую налаженную схему получения прибыли. Главной причиной названных сложностей является повышенный риск инновационной деятельности и отсутствие у предпринимателей гарантий защиты со стороны государства.

На наш взгляд, адресная поддержка конкретных инновационных идей могла бы стать лучшим способом государственного инвестирования в инновации, нежели традиционное вложение средств государственного бюджета в определенные субъекты РФ. В результате успешного стимулирования конкретных инновационных проектов экономически развитые субъекты, на территории которых они реализуются, получат дополнительную мотивацию к дальнейшему развитию. В то время как недостаточно развитые регионы перестанут получать простое финансирование, тем самым получат возможность самостоятельного развития [1].

Для увеличения стимула предприятий в ряде стран используют так называемый инновационный налог, который имеет следующий механизм: если предприятие не тратит определенную сумму на инновационные проекты, ее приходится отчислять в бюджет. Но существующая специфика не позволит безболезненно ввести подобный механизм потому, что у предприятия, занимающегося научными разработками, большие расходы, например, зарплата сотрудникам составляет $80 \%$ расходов предприятия [3].

Успешная конкуренция будет достигнута только в случае постоянного совершенствования национальной инновационной и инвестиционной систем, что, в свою очередь, предполагает активное участие государства в лице региональной власти [4]. Среди условий успешного развития региональной инновационной системы можно также выделить формирование и развитие сотрудничества между государственным, частным и исследовательским секторами бизнеса, которому способствует развитая инновационная инфраструктура (бизнес-инкубаторы и технопарки). Еще одним условием можно назвать создание и развитие программ коммерциализации инноваций.

К приоритетным направлениям Республики Татарстан в области инновационной политики принято относить: разработку информационных систем, производство машин и оборудования, производство оптического и электронного оборудования, а также медицину. Помимо названных, в область республиканских инновационных интересов включаются также сферы: создания новых материалов, нетрадиционных энергоресурсов и энергосберегающих технологий, новых производственных технологий, транспорта и связи [6]. Все указанные научно-технические направления совпадают с национальной инновационной политикой России.

В соответствии с законом РТ от 02.08.2010 № 63-3РТ «Об инновационной деятельности в Республике Татарстан» государство в лице татарстанских органов власти осуществляет поддержку субъектов инновационной деятельности. Возможными формами государственной поддержки выступают: прямое финансирование научных исследований, предоставление субъектам инновационной деятельности государственного имущества, предоставление консультационных услуг, осуществление мер по популяризации научно-технической деятельности в Республике Татарстан в средствах массовой информации и т. д. Финансовыми источниками поддержки инновационного бизнеса являются бюджет Республики Татарстан, а также иные привлекаемые средства, не запрещенные законодательством [8].

В случае дальнейшего успешного развития экономики региона и осуществления в полной мере запланированных идей объем ВРП в Татарстане с 2018 по 2020 год возрастет на $19 \%$ и к 2020 году достигнет 2 трлн рублей.

В начале 2015 года в Татарстан были привлечены иностранные инвестиции в размере 222,4 млн долл. США. Объем инвестиций в 2016 году составил 596 млн долл., в 2017 году 766,5 млн долл., прогнозируемый объем инвестиций на 2018 год - 988 млн долл. 
Для осуществления планируемых темпов роста экономики в республику на период 2015 -2018 годов необходимо привлечь инвестиций в объеме около 2 трлн рублей. Тогда в соответствии с планом к 2018 году инвестиционный прирост в основной капитал составит 23,6 $\%$ в сопоставимых ценах к уровню 2015 года.

Для поддержки инвесторов применяются инструменты по предоставлению налоговых льгот, то есть возможности в определенный период времени уплачивать налоги в меньшем размере. Так, субъектам, занимающимся инвестиционной деятельностью, реализующим инвестиционные проекты на территории РТ, согласно закону, правительство предоставляет льготы по:

1. Налогу на вновь приобретенное для реализации проекта имущество в размере $2,1 \%$ (снижение ставки налога с 2,2\% до $0,1 \%$ ).

2. Налогу на прибыль организаций в размере $4,5 \%$ в части, зачисляемой в бюджет РТ (снижение ставки налога с $18 \%$ до 13,5\%).

В инвестировании экономики республики в той или иной степени участвует более 50 государств. К числу наиболее активных инвесторов в последние годы можно отнести Германию (ее доля в объеме накопленных инвестиций составила почти $55 \%$ ), Соединенное Королевство (Великобританию) (19,1\%), Люксембург (7,6 \%) и Кипр (6,3 \%). В таблице 2 отражена динамика поступления иностранных инвестиций в предприятия Республики Татарстан.

Динамика поступления иностранных инвестиций в РТ

Таблийа 2

\begin{tabular}{|c|c|c|c|c|c|c|c|}
\hline & $\mathbf{2 0 1 2}$ & $\mathbf{2 0 1 3}$ & $\mathbf{2 0 1 4}$ & $\mathbf{2 0 1 5}$ & $\mathbf{2 0 1 4}$ & $\mathbf{2 0 1 6}$ & $\mathbf{2 0 1 7}$ \\
\hline Всего, тыс. долл. & 1679354 & 2593827 & 2240308 & 4149679 & 856836 & 4010000 & 893963 \\
\hline $\begin{array}{c}\text { Прямые, } \\
\text { тыс. долл. }\end{array}$ & 417923 & 722959 & 113345 & 146488 & 99569 & 3588500 & 408229 \\
\hline $\begin{array}{c}\text { Портфельные, тыс. } \\
\text { долл. }\end{array}$ & 27564 & 706,3 & 0,1 & 6,1 & - & 4500 & 5059,7 \\
\hline Прочие, тыс. долл. & 1233867 & 1870161 & 2126962 & 4003184 & 757266 & 417000 & 480574 \\
\hline
\end{tabular}

Примечание: составлено по данным Федеральной службы государственной статистики РФ.

Из таблицы видно, что иностранные инвестиции в республику находятся в положительной динамике, демонстрируют уверенный рост.

Заключение. Таким образом, для увеличения инвестиционной привлекательности Республики Татарстан необходимо:

1. Создание организационно-экономических предпосылок для привлечения капитальных вложений с целью воспроизводства основных фондов (отмена НДС, уменьшение процента ставки по кредиту, льготные налоговые системы и т. д.).

2. Создание конкурентной среды.

3. Проведение обязательной экспертизы и аудита выполнения инвестиционных проектов.

4. Создание и активная реализация инноваций.

5. Использование человеческого ресурса соответствующего качества и структуры.

6. Создание условий для технической модернизации потенциала собственности, поддержка и стимулирование со стороны государства.

7. Ориентация исследовательской среды на удовлетворение инновационных потребностей производства.

Литература

1. Абдуханова Н. Г. Государственно-частное партнерство - путь к инновачионному развитию жилищно-коммунального комплекса. - Российское предпринимательство. - 2015. - T. 16. - № 19. - С. $3217-3224$.

2. Балкизов М. Х., Бухонова И. И., Куянцев И. А. Региональная эконолика и ее инновационный потенциал // Известия Кабардино-Балкарского государственного аграрного университета им. В. М. Коко- 
ва. - 2016. - № 1 (11). - С. 55-59.

3. Белай О. С., Мухаметзянова Д. Д. Стратегии коммеричиализаџии инноваций и проблемы выведения инновачионных продуктов на рынок // Российское предпринимательство. - 2015. - T. 16. № 19. - C. 3209-3216.

4. Бондаренко В. В., Чакаев Р. Р., Лескина О. Н., Танина М. А., Юдина В. А., Харитонова Т. В. Роль региональных институтов развития в повышении инноваџионного потенщиала субъектов российской федерации // Региональная экономика: теория и практика. - 2018. - T. 16. - № 1 (448). - C. 83100.

5. Воронина Л. А., Золотарева И. Д. Экономика региональной науки и ее роль в инновационном развитии // Экономика: теория и практика. - 2016. - № 2 (42). - С. $24-31$.

6. Глазунова Е. 3., Зыкова Е. Н. Сравнительный анализ инвестиционной привлекательности регионов Приволжского федерального округа. Вектор экономики. - 2018. - № 1 (19). - С. 31 .

7. Гориков А. В. Инновационная экономика: региональная модель // Вестник Челябинского государственного университета. - 2004. - T. 8. - № 1. - C. 19-24.

8. Дуброва М. В. Инструменты финансового стимулирования инновационной деятельности региона // Экономика и управление: проблемы, решения. - 2018. - T. 4. - № 1. - С. 4146.

9. Идигова Л. М., Умаев М. А. Инновачионные механизмы привлечения инвестиций в региональную экономику // Агропродовольственная политика России. - 2013. - № 5 (17). - C. 79-81.

10. Ильина Е. В. Анализ деятельности и роль исполнительного комитета (на примере Нурлатского муниципального района Республики Татарстан) // Управление экономическими системами: электронный научный журнал. - 2018. - № 2 (108). - C. 25.

11. Макарова Е. С. Оченка инновачионного развития Республики Татарстан. - 2017. - № 3. - C. 4750.

12. Макарова Е. С. Фундаментальные и прикладные исследования кооперативного сектора экономики. - 2017. - № 3. - С. 47-50.

13. Маркарян В. Р. Инновационный подход в науке управления региональной экономикой // Актуальные проблемы и перспективы развития государственного управления. Сборник научных статей по материалам ежегодной международной научно-практической конференции. 2015. - C. 246-248.

14. Морозова Н. В., Алексеева А. Э. Региональная экономика в условиях перехода к инновационному типу развития, инновации и инвестиции. 2011. - № 3. - С. 33 - 35.

15. Носова С. С. Региональная и инновачионная экономика: кластеры, монография. - Москва, 2017.

16. Пель Е. В. Инновационная региональная экономика: мотиваџия научной молодежи // Управление человеческими ресурсами - основа развития инновачионной экономики. - 2010. - № 2. - C. 141-144.

17. Полунин Л. В. Влияние деятельности инновачионных предприятий на региональную экономику // Социильно-экономические явления и процессы. - 2012. - № 7-8 (41-42). - С. 13-139.

18. Сайфуллина Ф. М., Клещева О. А. Моделирование и практические обобщения в области инновационного развития инвестиционно-строительного комплекса // Российское предпринимательство. - 2016. - T. 17. - № 21. - С. 2865-2874.

19. Территориальный орган Федеральной службы государственной статистики по Республике Татарстан. [Электронньй ресурс]. Режим достуnа: http://tatstat.gks.ru/, свободньій. - Загл. с экрана.

20. Угольникова О. Д., Петров А. П., Угольников В. В. Инновационная экономика: региональные кластерные инициативы, монография. М-во образования и науки РФ, Санкт-петербургский гос. ун-т сервиса и экономики. - Санкт-Петербург, 2010.

21. Устинова Л. Н., Низамова А. Ш., Вирцев М. Ю. Алгоритм прогнозирования стратегии инновационной деятельности предприятий // Экономический анализ: теория и практика. - 2017. - T. 16. № 11 (470). - C. 2111-2122.

\section{References:}

1. Territorial body of the Federal State Statistics Service for the Republic of Tatarstan. [An electronic resource]. Access mode: http://tatstat.gks.ru/, free. Heading from the screen.

2. Abduhanova N. G. Public-Private Partnership - the path to the innovative development of the housing and utilities complex // Russian Entrepreneurship. 2015. T. 16. No. 19. P. 3217-3224.

3. Belay O. S., Mukhametzyanova D. D. Strategies for the commercialization of innovations and the problems of introducing innovative products to the market // Russian Entrepreneurship. 2015. T. 16. No. 19. P. 3209-3216.

4. Bondarenko V. V., Chakaev R. R., Leskina O. N., Tanina M. A., Yudina V. A., Kharitonova T. V. The Role of Regional Development Institutions in Increasing the Innovative Potential of the Subjects of the Russian Federation // Regional economy: theory and practice. 2018. T. 16. No. 1 (448). P. 83-100.

5. Glazunova E. Z., Zykova E. N. Comparative analysis of investment attractiveness of the regions of the Volga Federal District Economy vector. 2018. No. 1 (19). P. 31.

6. Dubrova M. V. Instruments of Financial Incentives for Innovation Activity in a Region // Economics and Management: Problems, Solutions. 2018. T. 4. No. 1. P. 41-46.

7. Ilina E. V. Activity Analysis and the Role of the Executive Committee (on the example of the Nurlatsky Municipal District of the Republic of Tatarstan) // Management of Economic Systems: an electronic scientific journal. 2018. No. 2 (108). P. 25.

8. Makarova E. S. Evaluation of the Innovative Development of the Republic of Tatarstan. 2017. No. 3. P. 47-50.

9. Makarova E. S. Fundamental and Applied Research of the Cooperative Sector of the Economy. 2017. 
No. 3. P. 47-50.

10. Saifullina F. M., Klescheva O. A. Modeling and practical generalizations in the field of innovative development of the investment and construction complex // Russian Entrepreneurship. 2016. T. 17. No. 21. P. $2865-2874$.

11. Ustinova L. N., Nizamova A. Sh., Virtsev M. Yu. Algorithm of forecasting the strategy of innovation activity of enterprises Economic analysis: theory and practice. 2017. T. 16. No. 11 (470). P. 2111-2122.

12. Pel E. V. Innovative Regional Economy: Motivation of Young Scientists, Managing Human Resources The Basis for the Development of an Innovative Economy. 2010. No. 2. P. 141-144.

13. Markaryan V. R. Innovative Approach to the Science of Regional Economy Management // In the collection: actual problems and prospects for the development of public administration a collection of scientific articles based on the materials of the annual international scientific-practical conference. 2015. P. 246-248.

14. Voronina L. A., Zolotareva I. D. Economics of regional science and its role in innovation development // Economics: theory and practice. 2016. No. 2 (42). P. 24-31.

15. Ugolnikova O. D., Petrov A. P., Ugolnikov V. V. Innovative Economics: Regional Cluster Initiatives, monograph // M-in Education and Science of the Russian Federation, St. Petersburg State // University of Service and Economy. St.-Petersburg, 2010.

16. Idigova L. M., Umaev M. A. Innovative mechanisms for attracting investment in the regional economy // Russia's agri-food policy. 2013. No. 5 (17). P. 79-81.

17. Morozova N. V., Alekseeva A. E. Regional economy in the transition to an innovative type of development, innovation and investment. 2011. No. 3. P. 33-35.

18. Gorshkov A. V. Innovative economy: regional model // Bulletin of Chelyabinsk State University. 2004. T. 8. No. 1. P. 19-24.

19. Polunin L. V. Influence of the activities of innovative enterprises on the regional economy // Socioeconomic phenomena and processes. 2012. No. 7-8 (41-42). P. 133-139.

20. Nosova S. Regional and innovative economy: clusters, monograph. Moscow, 2017.

21. Balkizov M. Kh., Bukhonova I. I., Kuyantsev I. A. Regional economy and its innovative potential, News of the Kabardino-Balkarian State Agrarian University. V. M. Kokova. 2016. No. 1 (11). P. $55-59$ 